\title{
How to implant neutrophil-to-lymphocyte ratio cut-off for COVID-19 to the laboratory information system
}

\section{Ozgur Aydin}

Department of Biochemistry, Kepez Public Hospital, Antalya, Turkey
Latest literature presents neutrophil-to-lymphocyte ratio (NLR) as an independent prognostic factor of morbidity and mortality in several conditions, including cancers and cardiovascular diseases [1, 2]. Yang et al. advised the integration of NLR to prognostic nomograms in managing patients with COVID-19. They found a cut-off value of 3.3 in their study [3]. While managing patients in a pandemic hospital, our laboratory followed the literature closely. We informed the clinicians about the new parameter and the decision limit and cited the research by Yang et al. In our hospital, NLR was not used previously, but it could easily be derived from the neutrophil count and lymphocyte count, which were routine parameters of complete blood count. NLR appeared on the patients' result pages as a separate parameter in a very short time. However, adopting the specific NLR cut-off value for patients with COVID-19 to the laboratory information system was problematic. Our software system offered age, gender and instrument as choices to create normal values or decision limits for any parameter in use. Within these options, it was impossible to implant a cut-off value for NLR that would appear "only" on the results page of patients with COVID-19 but no others. We experienced a failure in implanting a COVID-19 specific cut-off value to our laboratory information system with the available options. Our software writers created a new option that made it possible to match a cut-off value to an outpatient or inpatient clinic. As a pandemic hospital, our hospital was serving with units, namely "COVID-19 Outpatient Clinics". After using the new option, the NRL parameter was present on the result pages of every patient with a CBC, but the cut-off value 3.3 was present only for the patients of COVID-19 outpatient clinics.
Our efforts helped but did not solve the problem. Some inpatient clinics like Cardiology or Internal Medicine Clinics were converted for patients with COVID-19, but we never had a namely COVID-19 Inpatient Clinic. Thus, our solution did not work for inpatient clinics.

A perfect solution is to match the cut-off value to the ICD-10 code created for COVID-19. Thus, any patient with an ICD-10 code for COVID-19 will have the cut-off value on his or her results page whether inpatient or outpatient [4]. Up-to-date, clinicians use disease-specific cut-off values commonly, and they will use them much more often in the near future. Laboratories should evolve their information software systems accordingly. ICD-10 specific values, not only cut-off values or decision limits, but even critical values are mandatory in modern laboratories.

\section{References}

1. Durmus E, Kivrak T, Gerin F, Sunbul M, Sari I, Erdogan O. Neutrophil-to-Lymphocyte Ratio and Platelet-to-Lymphocyte Ratio are Predictors of Heart Failure. Arq Bras Cardiol 2015;105(6):606-13. [CrossRef]

2. Shen L, Zhang H, Liang L, Li G, Fan M, Wu Y, et al. Baseline neutrophil-lymphocyte ratio $(\geq 2.8)$ as a prognostic factor for patients with locally advanced rectal cancer undergoing neoadjuvant chemoradiation. Radiat Oncol 2014;9:295. [CrossRef]

3. Yang AP, Liu JP, Tao WQ, Li HM. The diagnostic and predictive role of NLR, d-NLR and PLR in COVID-19 patients. Int Immunopharmacol 2020;84:106504. [CrossRef]

4. Aydin O. ICD code specific reference ranges. Turk J Biochem 2019;44(5):722. [CrossRef]

Address for correspondence: Ozgur Aydin, MD. Department of Biochemistry, Kepez Public Hospital, Antalya, Turkey

Phone: +90 5432357629 E-mail: belozgur@hotmail.com ORCID: 0000-0002-6123-6186

Submitted Date: August 05, 2020 Accepted Date: August 16, 2020 Available Online Date: October 06, 2020

${ }^{\circ}$ Copyright 2020 by International Journal of Medical Biochemistry - Available online at www.internationalbiochemistry.com OPEN ACCESS This work is licensed under a Creative Commons Attribution-NonCommercial 4.0 International License. 